\title{
Report of Native Arteriovenous Fistulas on End Stage of Chronic Kidney Disease Patients in Indonesia \\ Muhammad Abdu*a, Mulaward Mulawardia
}

Introduction: Most CKD patients in the early stages are difficult to diagnose, so patients were found in the advanced stage of CKD. At this stage, treatment options only fall on hemodialysis and kidney transplantation. AV-shunt is indicated when long-term hemodialysis is required. Distal AV-shunt is an AV-shunt that is often used. This study aims to observe the proportion and characteristics of CKD stage $V$ patients undergoing AV-shunt.

Copyright (C) 2020, The Indonesian Society for Vascular and Endovascular Surgery

Method: This research is a retrospective descriptive study describing the data of patients with CKD who underwent the procedure of AV-shunt installation from the medical record department of RSUP Dr. Wahidin Sudirohusodo Makassar during the period January 2017 to December 2018. From the data obtained, it was recorded gender, age, number of CKD patients, number of CKD patients undergoing AV-shunt, postoperative complications, surgical failure, and pre comorbid factors of CKD patients (Diabetes Mellitus and Uric Acid).

Results: The results of this study show the facts in 2 years of observation, there were 327 people affected by CKD in Dr. Wahidin Sudirohusodo, and only $40.97 \%$ of patients who underwent the AV-shunt procedure. CKD sufferers were dominated by male sex $(n=204$; $62.4 \%$ ) compared to female ( $n=123 ; 37.6 \%)$. In percentage, male patients underwent AVshunt $(44 \%)$ greater than females (37\%). Complications were found in $13(10 \%)$ patients. A surgical failure occurred in 13 cases $(9.7 \%)$. Patients Diabetes mellitus is a major precomorbid factor found in $65 \%$ of patients, and Hyperuricemia is also found in $38.5 \%$ of patients.

Conclusion: From 327 patients CKD, only 134 patients underwent the AV-shunt procedure. CKD sufferers are dominated by the male gender. Most complications are bleeding and infection. Diabetes Mellitus is the leading precomorbidity factor most commonly found.

Keywords: AV-shunt, CKD Stage V, Diabetes Mellitus, Uric Acid https://doi.org/10.36864/jinasvs.2020.2.011

Correspondence: abdu.muhammad28@gmail.com

aM.D., Department of Surgery, Dr. Wahidin Sudirohusodo, South Sulawesi, Indonesia

\section{INTRODUCTION}

Chronic kidney disease (CKD) is defined as a persistent impairment of kidney function, in other words, abnormally elevated serum creatinine for more than 3 months or calculated glomerular filtration rate (GFR) less than $60 \mathrm{ml}$ per minute/1.73m2 [1]. Most CKD patients were not diagnosed in the early stages which later found in end stage renal disease (ESRD). At this time, hemodialysis and kidney transplantation are the only treatment options [2].

CKD is a major public health epidemic, with at least 1 in 10 people having some degree of kidney damage and this contributes substantially to adverse clinical and economic outcomes. The prevalence of CKD in the United States ranges around $4.7 \%$. Whereas in Pakistan, the prevalence of CKD is around $16.6 \%-25 \%$. CKD patients have limited life expectancy with an estimated life span of only about 8 years for those aged 40 to 4.5 years for those aged 64 years after initiation of dialysis $[2,3]$.
Some of the most common risk factors for CKD are diabetes mellitus, hypertension, and other causes such as glomerulonephritis, polycystic kidney disease, kidney vascular disorders, chronic urinary tract obstruction, vesicoureteral reflux, and recurrent pyelonephritis [1]. However, at this time many new risk factors have also been investigated, such as elevated uric acid and gout [4].

Nearly half a million people need hemodialysis with around 100,000 new cases of late stage CKD (ESRD) each year. Hemodialysis can be done through a double lumen catheter (DLC) in the subclavian vein or the internal jugular vein. However, this technique is only suitable for short-term use [5]. AV-shunt is indicated when long-term hemodialysis is required. In addition, there are also other techniques, namely peritoneal dialysis (PD), which have a lower cost than hemodialysis (HD), but this therapy is still less popular today [6].

There are several types of access to arteriovenous hemodialysis (AV). Of the types of AV 
access, autogenous AV access has a higher level of patency and a lower risk of complications when compared to prosthetic arterial access and a lower risk of infection compared with temporary central venous catheters (CVC) [7].

A thorough patient history and physical examination are important before surgery. The patient's dominant extremity must be well considered, as well as a history of previous interventions or injuries that might affect the location of potential access. Physical examination with a tourniquet is used to assess the cephalic and basilica veins. A thorough pulse examination including an Allen test must be done to assess the arterial flow towards the hand. Extensive collateral vessels, edema, and a history of a previous central venous catheter (CVC) can signal central stenosis and potential problems with planned AV access on the extremity [7].

Distal AV-shunt is an AV-shunt that is often used, namely radial-cephalic fistula, which is anastomosis of the radial arteries and cephalic veins on the wrist. This AV-shunt is also often referred to as a Cimino fistula. If the distal cephalic vein is inadequate for manufacturing distal fistulas, proximal variants such as brachial-cephalic fistula or brachialbasilica fistula can be used. Fistula maturation is defined in the rule of $6 \mathrm{~s}$ which includes [7] flow greater than $600 \mathrm{~mL}$ per minute, diameter of more than $6 \mathrm{~mm}$, is less than $6 \mathrm{~mm}$ under the skin, $6 \mathrm{~cm}$ away from the vein for cannulation, and all of the above are obtained within 6 weeks.

There are also several AV-shunt complications that may occur, namely: early and slow AV thrombosis, venous hypertension, arterial steal syndrome, ischemic monomelic neuropathy, pseudoaneurism, bleeding, seroma, and infection [7].

\section{METHOD}

This research is a retrospective descriptive study describing the data of patients with CKD who underwent the procedure of $\mathrm{AV}$-shunt installation from the medical record department of RSUP Dr. Wahidin Sudirohusodo Makassar from the period January 2017 to December 2018. From the data obtained, gender, age, number of CKD patients, number of CKD patients who underwent AV-shunt, and risk factors for CKD patients (Diabetes Mellitus and Gout) are recorded. History, physical examination of arteries and veins to assess the viability of blood vessels before the AV-shunt procedure. Investigations such as ultrasound and upper limb venous doppler ultrasound are needed in some special cases, namely obese patients, weak or poor pulsation, history of thrombophlebitis, history of previous AV-shunt surgery. The collected data is processed, analyzed and presented in tables and narratives. Then compared with results from various literature.

\section{RESULTS}

From the results of a retrospective study of CKD cases during the period January 2017 to December 2018 at Dr. Wahidin Sudirohusodo, Makassar obtained 327 samples, with a total of 134 CKD cases undergoing AV-shunt procedures. The following evaluation results are outlined in the form of a patient characteristics table below.
Table 1. Number of CKD Cases in RSUP Dr. Wahidin Sudirohusodo Makassar from the period January 2017 to December 2018.

\begin{tabular}{|c|c|c|c|c|}
\hline \multirow[t]{2}{*}{ Period } & \multirow[t]{2}{*}{ Age group } & \multicolumn{3}{|c|}{ Total $(n=327)$} \\
\hline & & Male & Female & Total \\
\hline \multirow{9}{*}{$\begin{array}{l}\text { January - } \\
\text { December } \\
2017\end{array}$} & $0-10$ years & 0 & 0 & 0 \\
\hline & $11-20$ years & 0 & 0 & 0 \\
\hline & $21-30$ years & 6 & 3 & 9 \\
\hline & $31-40$ years & 22 & 11 & 33 \\
\hline & $41-50$ years & 22 & 14 & 36 \\
\hline & $51-60$ years & 39 & 25 & 64 \\
\hline & $61-70$ years & 33 & 20 & 53 \\
\hline & $71-80$ years & 5 & 2 & 7 \\
\hline & $81-99$ years & 1 & 0 & 1 \\
\hline \multirow{9}{*}{$\begin{array}{l}\text { January - } \\
\text { December } \\
2018\end{array}$} & $0-10$ years & 1 & 1 & 2 \\
\hline & $11-20$ years & 0 & 2 & 2 \\
\hline & $21-30$ years & 13 & 11 & 24 \\
\hline & $31-40$ years & 11 & 11 & 22 \\
\hline & $41-50$ years & 15 & 8 & 23 \\
\hline & $51-60$ years & 17 & 9 & 26 \\
\hline & $61-70$ years & 18 & 4 & 22 \\
\hline & $71-80$ years & 0 & 1 & 1 \\
\hline & $81-99$ years & 1 & 1 & 2 \\
\hline TOTAL & & 204 & 123 & 327 \\
\hline
\end{tabular}

Table 2. Number of CKD patients who undergo the AV-shunt procedure at Dr. Hospital. Wahidin Sudirohusodo during the period January 2017 to December 2018.

\begin{tabular}{llll}
\hline Period & \multicolumn{3}{c}{ Total $(\mathbf{n = 1 3 4 )}$} \\
\cline { 2 - 4 } & Male & Female & Total \\
\hline January - December 2017 & 49 & 22 & 71 \\
January - December 2018 & 41 & 22 & 63 \\
\hline TOTAL & $\mathbf{9 0}$ & $\mathbf{4 4}$ & $\mathbf{1 3 4}$ \\
\hline
\end{tabular}


Table 3. Complications of AV-shunt procedure in CKD patients at Wahidin Sudirohusodo General Hospital during the period January 2017 to December 2018.

\begin{tabular}{llll}
\hline \multirow{2}{*}{$\begin{array}{l}\text { Post-surgery } \\
\text { complication }\end{array}$} & \multicolumn{3}{l}{ Total $(\mathbf{n = 1 3 4 )}$} \\
\cline { 2 - 4 } & Male & Female & Total \\
\hline Thrombosis & 1 & 1 & 2 \\
Venous hypertension & 0 & 0 & 0 \\
Pseudoaneurism & 2 & 3 & 5 \\
Bleeding, Seroma, Infection & 3 & 3 & 6 \\
Without complication & 78 & 34 & 121 \\
\hline TOTAL & 90 & 44 & 134 \\
\hline
\end{tabular}

Table 4. Failure of AV-shunt function in CKD patients at Wahidin Sudirohusodo General Hospital during the period January 2017 to December 2018.

\begin{tabular}{llll}
\hline \multirow{2}{*}{ Surgery failure } & \multicolumn{3}{l}{ Total $(\mathbf{n = 1 3 4 )}$} \\
\cline { 2 - 4 } & Male & Female & Total \\
\hline AV-shunt Failure & 8 & 5 & 13 \\
New Case & 82 & 39 & 121 \\
\hline Total & 90 & 44 & 134 \\
\hline
\end{tabular}

Table 5. Premorbid Factors of CKD patients in Dr. Wahidin Sudirohusodo during the period January 2017 to December 2018.

\begin{tabular}{llll}
\hline \multirow{4}{*}{ Premorbidity } & \multicolumn{3}{c}{ Total $(\mathbf{n = 3 2 7})$} \\
\cline { 2 - 4 } & Male & Female & Total \\
\hline Diabetes melitus & 145 & 67 & 212 \\
Hyperuricemia & 68 & 58 & 98 \\
Others & 9 & 8 & 17 \\
\hline
\end{tabular}

\section{DISCUSSION}

In this study the highest number of patients was obtained in the age group 51-60 years (men $27.5 \%$ and women $26.8 \%$ ). Then followed by the group aged $61-70$ years for male patients and the age group 41-50 years for female patients. Most CKD paatients are men $(62.38 \%)$. A retrospective observational study conducted by Saharabudhe et al. showing that of the 271 CKD cases that were found on average 55 years [8]. Research conducted by Abrol et al. and Baghel et al. It appears that the 41-50 year age group has the most CKD increase, accepted with the $51-60$ year age group $[9,10]$. The third study shows the type of male study [8-10].

In this study it was found that only about $40.97 \%$ of CKD patients underwent AV-shunt, with a higher percentage in men (44\%) than in women $(37 \%)$. This is somewhat different from the study conducted by Shafi et al, who found that $57.6 \%$ of patients were willing to undergo an AV-shunt. The study also noted that one of the factors that caused patients not to have an AV-shunt was a low level of education and socio-economics [2]. However, in this study it is unknown what causes the low number of patients who want to do AV-shunt.

Anastomosis can be done between the arteries and veins in one of two techniques, namely side to side anastomosis or anastomosis side of the artery to the end of the vein. The closeness and diameter of blood vessels are decisive in considering the technique used for anastomosis. End-to-end anastomosis is no longer used. This is due to the need for distal flow ligation, usually the radial arteries, and have a higher rate of complications [7].

In this study, it is known that only $10 \%$ of the number of AV Shunts that have complications, consisting of 6 cases of bleeding / stromal / infection, 5 cases of pseudoaneurism, 2 cases of AV Shunt thrombosis. In the study of Ibrahim et al., The complications found were edema and red spots in the area of surgery for 8 cases each, then pseudoaneurism for 5 cases and bleeding / infection for 5 cases. The study conducted by Khadatkar et al found complications of calcification / atherosclerosis of blood vessel walls in 5 cases, they also found psuedoaneurism (5 cases), ecchymosis (8 cases), edema ( 8 cases), infection / bleeding ( 5 cases). In the study of Mahakalkar et al more complications are 
hand edema and redness on the operative side. The rate of complications in radiocephalic fistula cases is higher than that of the brachiocephal fistula in several serial case reports [12].

In this study it is known that about $9.7 \%$ of the total sample that experienced a failure of surgery. This may be due to the risk factors that the patient has such as: sex, age, DM type 2. A case study conducted by Gunawan et al found that age, female sex and diabetes. In addition, failure of surgery can also be triggered if the patient is obese and of African descent [13]. In addition, according to Pirozzi, et al, AV-shunt failure can occur due to low flow due to inflow or outflow stenosis, a very deep location of the vein and diversion flow to accessory veins. Low flow is associated with stenosis [14].

In this study, Diabetes Mellitus was the main cause of CKD in $64.8 \%$ of patients, followed by elevated uric acid levels which occurred in $29.9 \%$ of patients. In the same study, Sahasrabudhe et al also showed that $48.7 \%$ of patients had diabetes mellitus which later caused CKD [8]. In addition, the research of Arbol et al. and also Baghel et al. showed that CKD was most commonly caused by DM glomerulonephritis, but Arbol et al found that the second most common cause was hypertension $[9,10]$. Stack et al. showed that patients with hyperuricemia had a $29 \%$ higher risk of suffering from advanced CKD than patients without gout (HR, 1.29, 95\% CI 1.231.35) [4].

\section{CONCLUSION}

The results of this study indicate that in 2 years of observation, there were 327 CKD cases in Dr. Wahidin Sudirohusodo and only 134 patients underwent the AV-shunt procedure. CKD patients are mostly men. Most complications are bleeding/infection. Diabetes mellitus is the main precomorbid factor.

\section{CONFLICT OF INTEREST}

The author states the original work, and there is no conflict of interest in doing this research.

\section{ORCID ID OF AUTHORS}

Muhammad Abdu

https://orcid.org/0000-0002-6263-221X

Mulawardi Mulawardi

https://orcid.org/0000-0002-9482-0012

\section{REFERENCES}

1. Bindroo S, Challa HJ. Renal Failure. StatPearls [Internet]. 2020. p. 1-8.

2. Shafi ST, Saleem M, Anjum R, Abdullah W, Shafi T. Refusal of Hemodialysis by Hospitalized Chronic Kidney Disease Patients in Pakistan. Saudi J Kidney Dis Transplant. 2018;29(2):401-8.

3. Ho C, Martinusen D, Lo C. A Review of Cannabis in Chronic Kidney Disease Symptom Management. 2019;

4. Stack AG, Johnson ME, Blak B, Klein A, Carpenter L, Morlock R, et al. Gout and the risk of advanced chronic kidney disease in the UK health system : a national cohort study. 2019;

5. Butala BP, Shah VR, Solanki B, Kalo J. Internal jugular vein thrombosis: a complication of temporary hemodialysis catheter. J Anaesthesiol Clin Pharmacol. 2015;31(2):275-6.

6. Wong B, Ravani P, Oliver MJ, Holroyd-Leduc J, Venturato L, Garg AX, et al. Comparison of Patient Survival Between Hemodialysis and Peritoneal Dialysis Among Patients Eligible for Both Modalities. Am J Kidney Dis [Internet]. 2018;71(3):344-51. Available from: https://doi.org/10.1053/j.ajkd.2017.08.028

7. Segal M, Qaja E, Heights W, Heights W. Types of Arteriovenous Fistulas. StatPearls [Internet]. 2020. p. $2-5$.

8. Pirozzi N, Medina JG, Menè P. Impaired maturation of distal radio-cephalic fistula for haemodialysis: a review of treatment options. J Nephrol. 2017;30(1):45-51.

9. Sahasrabudhe P, Dighe T, Panse N, Patil S. Retrospective analysis of 271 arteriovenous fistulas as vascular access for hemodialysis. 2013;23(3):191-6.

10. Abrol S, Sharma R. A study of cutaneous manifestations in chronic kidney disease patients on hemodialysis. 2018;8(1):13-6.

11. Baghel N, Awasthi S, Kumar SS. Cutaneous manifestations in patients with chronic kidney diseases on haemodialysis. 2017;5(4):1673-8.

12. Browne LD, Bashar K, Griffin P, Kavanagh EG, Walsh R, Walsh MT. The Role of Shear Stress in Arteriovenous Fistula Maturation and Failure: A Systematic Review. PLoS One. 2015;1-24.

13. Ibrahim K, Fatima S, Aman B. Functional Outcome of Arteriovenous Fistula For Maintenance Hemodialysis In End Stage Renal Disease. J Surg Pakistan. 2018;3:1-4.

14. Gunawan A, Ngutamani SY, Rifai A, Nursamsu. Angioplasty in CKD patients with immature AV fistula: A Case Repor. Indones J Kidney Hypertens. 2019;II:8-12. 